\title{
EXPERIMENTAL AND NUMERICAL STUDIES ON WAVE PROPAGATION OVER COARSE GRAINED SLOPING BEACH
}

\author{
Jian-Wu Lai ${ }^{1}$, Tai-Wen Hsu ${ }^{2}$ and Yuan-Jyh Lan ${ }^{2}$
}

\begin{abstract}
In this paper, the hydrodynamics and turbulence on wave propagation over coarse grained sloping beach is investigated by both experimental and numerical methods. The coarse grained sloping beach was conducted over a 1:5 smooth inclined bottom with two layers of spherical balls. A set of newly and rarely experimental data for the distribution and evolution of the wave and velocity field over porous sloping beach were measured in this study. The particle image velocimetry (PIV) and digital image process (DIP) techniques are employed to measure the flow field and free surface both inside and outside regions for a coarse grain porous sloping bed. Eleven fields of views (FOVs) were integrated to represent the global results converting the entire propagating waves from the outer to the inner surf zones and swash zones. In addition, a high-resolution CCD Camera was constructed to capture wave propagating images continuously. Subsequent digital image processing (DIP) techniques that including image enhancement, coordinate transformation, edge detection and sub-pixel concept for resolution advancement were developed to analysis the image and get the information of wave motions. In this experimental study, the PIV and DIP techniques offer a possibility for measuring full scale spatio-temporal information of the wave motions and velocity field within / without the porous sloping bed without instructive instrument. Furthermore, the FLOW-3D which based on the Navier-Stokes equations was adopted for CFD computations. The direct three-dimensional simulations were employed for simulating wave profile and velocity field for the sloping beach. Numerical results were favorably compared with experiments to examine the validity of the model. According to the comparison of the wave and velocity data of hydraulic physical model with computational results, the direct three-dimensional simulations method can offer results much agreement with the experimental data in the global regions. The results showed that direct three-dimensional simulations can resolve the wave and velocity profile more complete and reasonable descriptions from outer to the inner porous layer and it is true no matter in the surf zone, swash zone and within the porous layer. Moreover, according to the experimental analysis, the process of the turbulence characteristics of the maximum turbulent kinetic energy, turbulent kinetic energy dissipation rate and turbulence intensity occurred between the toe of breaker and surface of porous layer. In addition, general discussion of hydrodynamics and turbulence on wave propagation over coarse grained sloping beach and impermeable sloping bed were investigated with the results of direct three-dimensional simulations in this study. The results showed that wave propagation over coarse grained sloping beach effects the breaker types in the shallow water, i.e. the steepening and overturning of the front face due to plunging breaker over impermeable sloping beach becomes indistinctively and the breaker type transform into the collapsing type. Besides, the dissipation of wave energy due to the role of infiltration and friction are significant differences from surf zone to swash zone between the coarse grained and impermeable sloping beach.
\end{abstract}

Keywords: coarse grained sloping beach, wave transformation, turbulence characteristics, particle image velocimetry, digital image process

\section{INTRODUCTION}

On the earth, most of coastal zones are mainly in the sandy beach. However there are still existing some beaches covered with coarse grained materials. All over the world, many countries such as, British, Japan and Taiwan have wide spreading natural gravel beaches. On these beaches, the diameters are 10 times larger than the sandy beach. And the near-shore hydrodynamic characteristics and topographic changes are significant differences. Furthermore, artificial porous structures, for example, revetment, caisson, offshore breakwater and submerged breakwater are constructed for protecting coastal zone. That is because these structures have pores up to the effect of reducing wave energy.

Study on wave over porous material experimental method was beginning on the reflection and transmission of porous bed/structures since 40 years ago (e.g., Iwasaki and Numata 1970; Dattartri et al. 1978). However, the traditional, intrusive instruments limit the study of flow around porous layer in the lab. Instead of intrusive tools, the development of Particle Image Velocimetry (PIV), a measurement technique, which allows for capturing velocity information of whole flow fields in fractions of a second, has begun in the eighties of the last century. On the other hand, the numerical study on wave over porous material may roughly divide into four categories. Firstly, wave energy dissipation due to the leakage on porous bottom (Putnam 1949; Reid and Kajiura 1957). Secondly, linearized porous flow equations which consider both inertial force and resistance force in the porous media (e.g., Sollitt and Cross 1972; Madsen 1974; Wurjanto and Kobayashi 1993; Tsai et al. 2006). However, these kinds of studies have some disadvantage on can not describe nonlinear wave

\footnotetext{
${ }^{1}$ Dept. of Civil Engineering, Nagoya University, Furo-cho, Chikusa-ku, Nagoya 464-8603, JAPAN

${ }^{2}$ Dept. of Hydraulic and Ocean Engineering, National Cheng Kung University, Tainan 701, Taiwan.
} 
deformation and detail of non-Darcy flow. In contrast, non-linear models for porous media play a main role in this decade (Sakakiyama et al. 1991; Sakakiyama and Kajima 1992; Liu et al. 1999; Van Gent $\left.1995^{\mathrm{a}, \mathrm{b}}\right)$. For the application on wide field, 2DH wave filed (e.g. extended mild slope eq.) are incorporated with porous effect, however the model are limited in application and development due to the assumption of linear wave theory (Rojanakamthorn et al. 1989; Losada et al. 1996; Mendez et al. 2001).

In past decades, compare with analytical method and computational method, the experimental information about pore velocity is limited due to its difficulties on measuring velocity within porous media by the traditional instruments. To overcome this embarrasses, non-invasive instruments, i.e., particle image velocimetry (PIV) and Fiber Laser Doppler Velocimetry (FLDV) are adopted. In order to measure the velocity field around the porous media, two kinds of experimental skills are often used. One is the refractive index matching technique which can measure the complete flow filed even though the view of laser sheet is shelter behind the structure (Wang and Khalili 2003). However, the specific liquid and structure are needed. Such kind of technique is limited in open channel and small scale tank. Instead of refractive index matching technique, a much easier way may be applied (Losada et al. 1995). That is the well-alignment of porous material.

In this paper, the hydrodynamics and turbulence on wave propagation over regular porous medium made of uniform coarse grained sloping beach is investigated by both experimental and numerical methods. This study has two main objectives, namely an attempt to integration of Digital Image Process, DIP and Particle image velocimetry, PIV schemes and applied it to measure the wave propagation and flow field on coarse grained sloping beach. Secondly, a Navier-Stokes equation based CFD numerical model Flow-3D was also employed for favorably comparison between experimental and numerical results.

\section{EXPERIMENTAL SETUP}

This section describes the experimental facilities and analysis techniques used in the study. Comprehensive introductions are not only the general facilities but also the DIP/PIV algorithms. Furthermore, the verification and validation of the experiments are also presented in this section.

\section{Experimental arrangement}

The experiment was conducted in a glass-walled wave flume having a dimension of $25 \mathrm{~m}$ long, $0.6 \mathrm{~m}$ high and $0.5 \mathrm{~m}$ wide in a laboratory of National Cheng Kung University. A piston- type wave generator is equipped on the right end to generate regular and irregular waves and a porous absorber of 1:8 slope is placed on the left end to dissipate wave energy from reflection. The coarse grained sloping beach model was deployed at a distance of $14 \mathrm{~m}$ from the wave board. The experimental setup are water depth $d=32 \mathrm{~cm}$. The incident wave period is $1.0 \mathrm{sec}$ and wave heights, $H_{i}$, are taken as 3.86 and $7.75 \mathrm{~cm}$, respectively.

Figure 1 presents the definition sketch of coarse grained sloping beach model. The model is constructed with two layers of well arrangement balls over a 1:5 slope. The diameter of spherical ball is $D=7.9 \mathrm{~cm}$ and the center-to-center distance of each ball is $8.0 \mathrm{~cm}$. And the intrinsic permeability $K_{p}$ and turbulent drag coefficient $C_{f}$ for the coarse grained model were obtained from steady flow water-head experiments. The values of $K_{p}$ and $C_{f}$ are $2.836 \times 10-3 \mathrm{~cm}^{2}$ and $4.306 \times 10^{-2}$, respectively.

Velocity fields under wave propagating over coarse grained sloping beach were measured using particle image velocimetry (PIV) technique. Eleven fields of view (FOVs) were integrated into a global representation covering from the outer to the inner surf zone and swash zone. The size of FOV is about $28 \times 21 \mathrm{~cm}$. Synchronization between PIV and other instruments (such the wave paddle motion or wave gauge) became a crucial point for the success of measurements. The synchronization between different instruments was achieved using programmable data acquisition (DAQ) system developed in software Labview (National Instrument, NI). The DAQ board used here was a high-accuracy multifunction board optimized for 16-bit analog input accuracy (NI, PCI-6014). The maximum scan rate of the analog input was $200 \mathrm{kS} / \mathrm{s}$ for multichannel inputs and it also has two 16-bit analog outputs $(10 \mathrm{kS} / \mathrm{s})$. A differential mode was used for analog measurements to reduce the background electric noise. In particular, 24-bits, $20 \mathrm{MHz}$ counters were synchronized with the DAQ board to generate highly accurate and synchronized TTL triggers used to control the CCD, pulsed laser or other instruments. In addition, the system had a function to allow the surface or PIV measurements being delayed with a preset time to skip unnecessary data. 

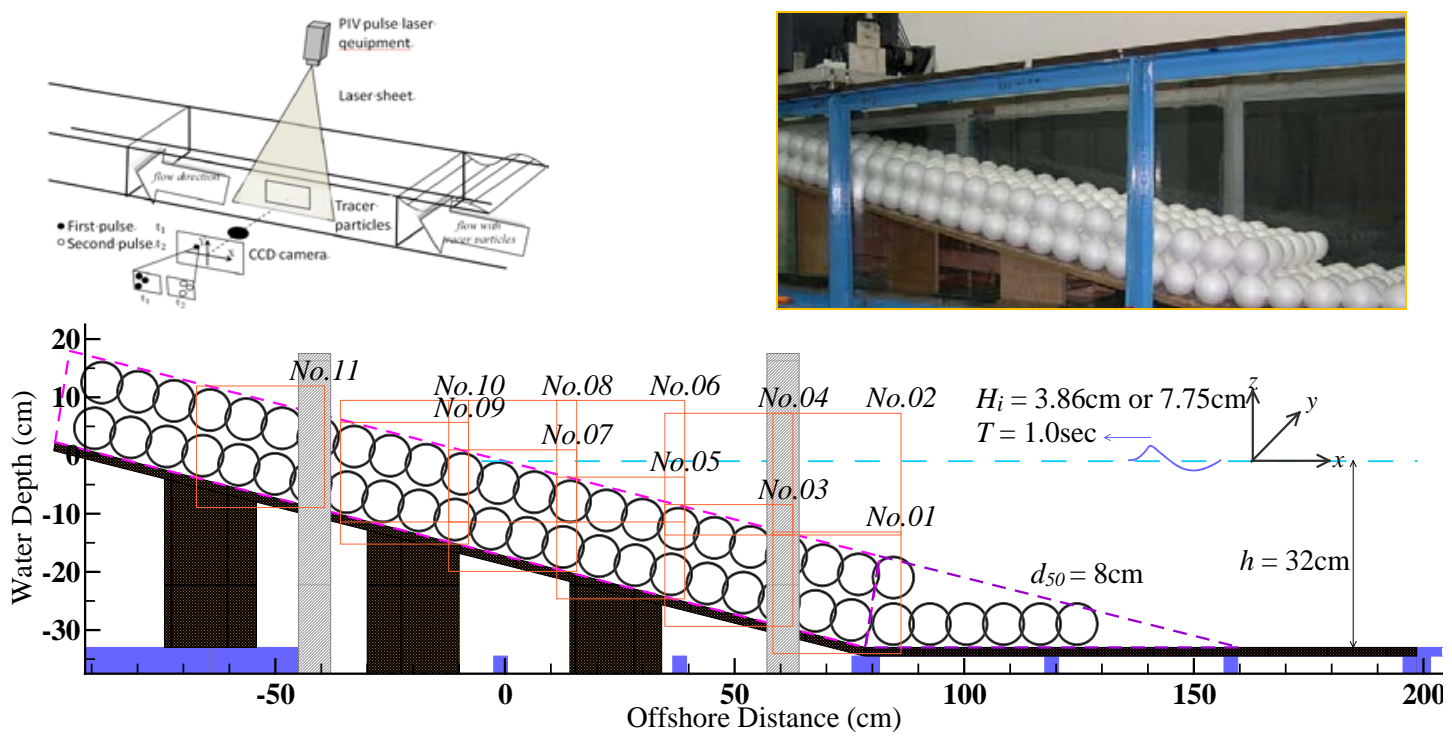

Figure 1. Schematic diagram of the experimental arrangement.

\section{Digital image-based measurement systems}

In this study, digital image processing (DIP) techniques that including image enhancement, coordinate transformation and edge detection (water surface) are employed to analysis the image and get the information of water surface motions.

During the measuring process, the captured images of the CCD camera would usually be distorted due to the curvature of the CCD camera's lens, such as pincushion distortion or barrel distortion; this leads to deviations of the measured results. Thus, the geometric calibration of the CCD camera is very important for integrating FOVs and measuring water surfaces. In general, the DLT (Direct Linear Transform) algorithm (1971) is simpler and widely used in camera calibration. Following the DLT algorithm, for a X-Z planar projective transformation, the relationships between image and world coordinates are defined as Equation (1)

$$
\begin{aligned}
& X=\frac{b_{1} x+b_{2} z+b_{3}}{b_{4} x+b_{5} z+1} \\
& Z=\frac{b_{6} x+b_{7} z+b_{8}}{b_{4} x+b_{5} z+1}
\end{aligned}
$$

where $(X, Z)$ are the image coordinates and $(x, z)$ are the world coordinates, and the 8 coefficients, $b_{i}$ with $i=1,2, ., 8$, are the functions of camera parameters. If $n(n \geq 4)$ pairs of coordinate points which be known, i.e. $\left(x_{1}, Z_{1}\right),\left(X_{1}, Z_{1}\right), \ldots\left(X_{n}, Z_{n}\right),\left(X_{n}, Z_{n}\right)$, then the coefficients can determined by a least squares algorithm. Figure 2 shows the original distortion image and the orthoimage after coordinate transformation.
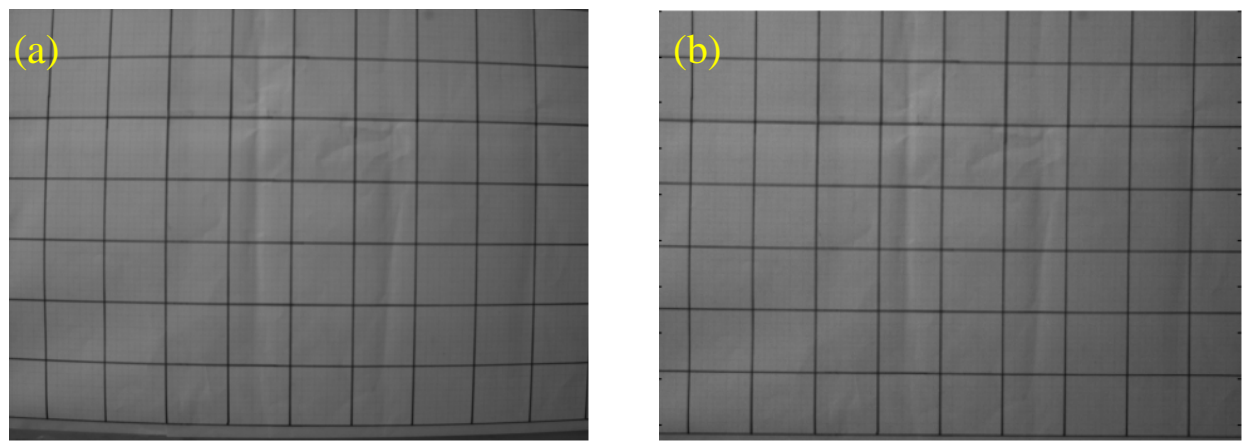

Figure 2. Example of (a) original distorted image and (b) corrected image by the DLT algorithm. 


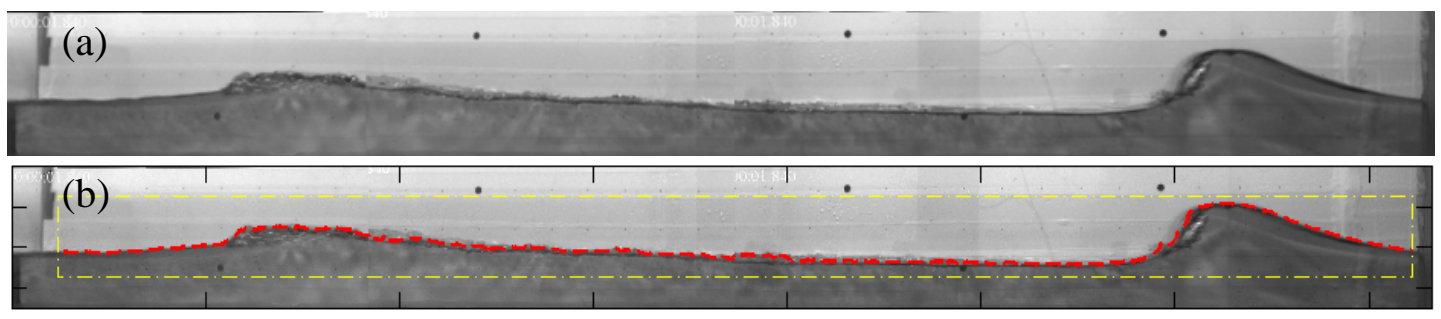

Figure 3. Comparison of water surface between the integrated image and water surface detection results at the wave motion status.

After integrated image into a global representation, the threshold values of water surface between the interface of air and water in each time were calculated by using Otsu (1978) algorithm. Then, the water surface profile could be calculated on the basis of the threshold values. Figure 3 shows the comparison of water surface between the mosaicked image and surface detection by Otsu edge detection algorithm at the wave motion status. The result shows that water surface detection results agrees with the surface as seen in the integrated images.

On the other hand, the PIV system, the cross-correlation-based algorithm is used to calculate the displacement of the particles after an image pair of two successive images is captured with single laser exposure on each straddling image frame and the second exposure is delay with a $\Delta t$ to the first laser exposure. Each image of the image pair is split into several interrogation windows which usually a square with size of proportional to power of 2. This takes advantage of evaluating the cross-correlation coefficient by the fast-Fourier-transform (FFT). In this PIV experiment, each image pair was crosscorrelated with a $32 \times 32$ pixel interrogation window and 50\% overlap between adjacent windows. Commercial software from TSI Inc. was used for the velocity field processing. In the process, a zeropadding mask and a Gaussian-peak algorithm were employed to increase the efficacy. A global range filter (set about $\pm 1 \mathrm{~m} / \mathrm{s}$ ) and a local median filter ( $3 \times 3$ window) was employed to remove spurious velocity vectors. The spatial resolution of the velocity measurements is $174.21602 \mu \mathrm{m} / \mathrm{pixel}$.

\section{Verification and validation of experimental system}

The crucial point for the success of this experiment includes repeatability and synchronization between PIV system and the wave paddle motion. Figure 4 show the time series of the measured surface elevations of 34 test runs in front of the sloping beach. In this figure, the wave gauge data of different test runs are plot as solid lines, and hollow circles circle are the average of 34 test runs. To ignore some electrical noise, the variation between runs is so small that the difference can not be distinguished visually. For the first wave that pulse laser illuminated, the standard deviation of the wave height and period are $0.083 \mathrm{~cm}$ and $0.006 \mathrm{sec}$, respectively. Table 1 summarizes the repeatability of wave generation in the wave tank.

In order to validate and check the DIP/PIV algorithm of the digital image-based measurement system settings we adopted in the study, a series of linear wave propagating in a constant water depth was tested and compared with the small amplitude wave theory. Fig. 5 shows the comparisons between the measured and theoretical results of the surface elevations and vertical profile velocity in $u$ and $w$ components. The results show that the measured surface profile by the DIP edge detection and the measured velocity by the PIV are well fitted to the theoretical results. This indicates the DIP/PIV system and settings used in the study are adequate for water surface and velocity measurements.

\begin{tabular}{|c|c|c|c|c|c|}
\hline \multicolumn{7}{|c|}{ Table 1. Repeatability of wave generation in the wave tank. } \\
\hline & $\eta_{\text {crest }}(\mathrm{cm})$ & $\eta_{\text {through }}(\mathrm{cm})$ & $t_{\text {crest }}(\mathrm{sec})$ & $H(\mathrm{~cm})$ & $T(\mathrm{sec})$ \\
\hline Min. & 3.87 & -3.23 & 25.30 & 7.06 & 0.98 \\
Max. & 4.09 & -3.16 & 25.34 & 7.32 & 1.00 \\
Avg. & 3.978 & -3.195 & 25.32 & 7.173 & 0.996 \\
STDEV, $\sigma$ & 0.067 & 0.023 & 0.0167 & 0.083 & 0.006 \\
\hline
\end{tabular}




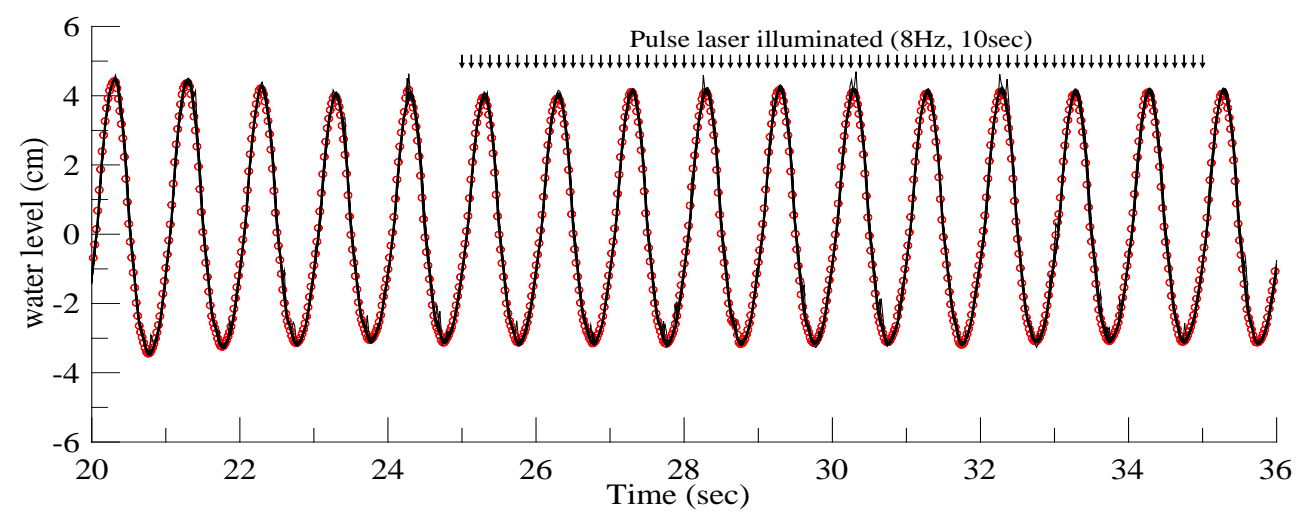

Figure 4. Performance and repeatability validation of the experimental wave tank.
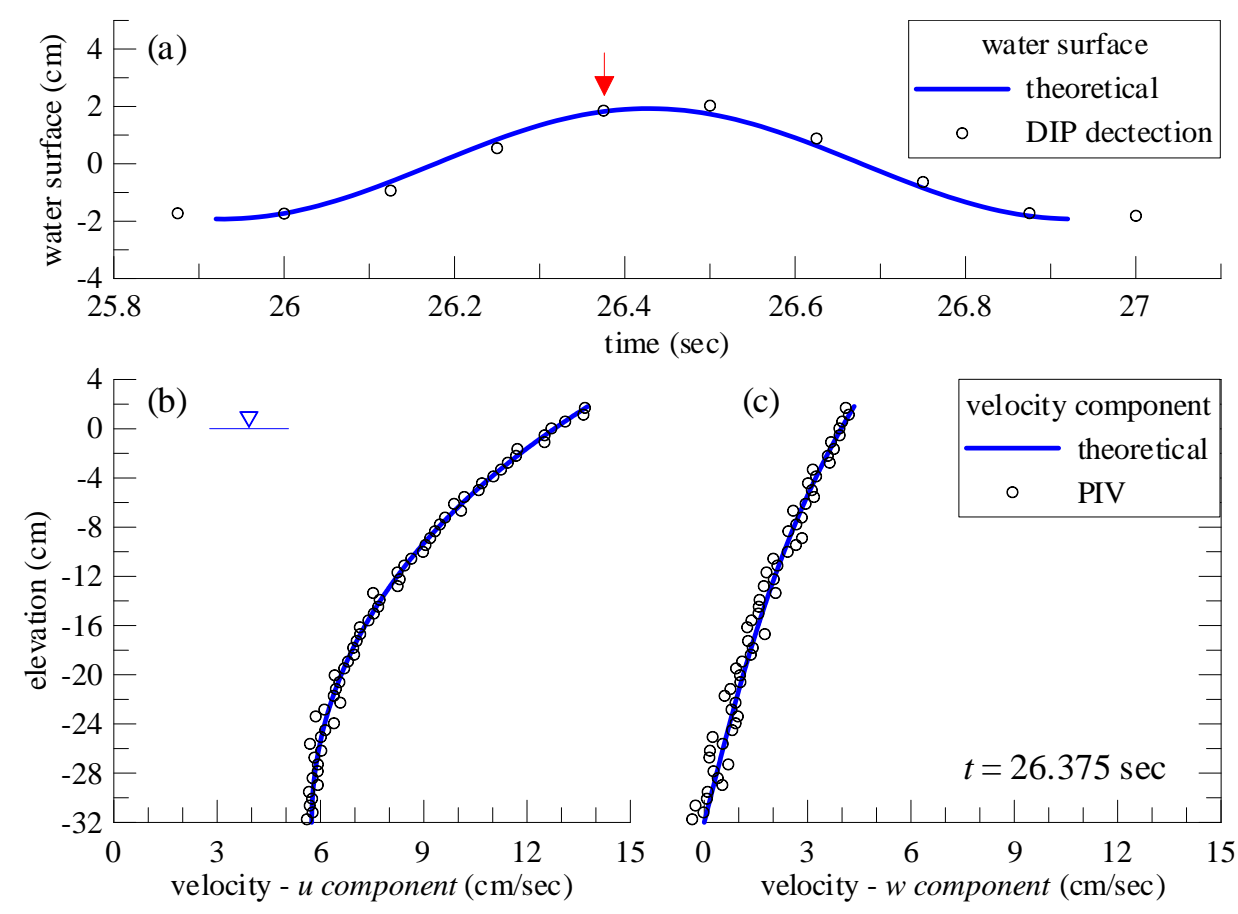

Figure 5. Comparison of (a) water surface and (b)(c) velocity profile between the digital image-based measurement system and small amplitude wave theory.

\section{NUMERICAL IMPLEMENTATION}

In this study, the FLOW-3D which based on the Navier-Stokes equations was adopted for computational fluid dynamics (CFD) computations. Direct three-dimensional simulations were employed for simulating wave propagating, velocity field and turbulence characteristic over coarse grained sloping beach respectively.

\section{FLOW-3D}

FLOW-3D from Flow Science, Inc. has several distinguishing features enables highly accurate simulations for investigating the dynamic behavior of liquids and gases in a wide range of industrial applications and physical processes. Those are TruVOF, FAVOR ${ }^{\mathrm{TM}}$ and multi-block meshing. FLOW3D uses special numerical methods to track the location of fluid and solid surfaces and to apply the proper dynamic boundary conditions at those surfaces. TruVOF incorporates major improvements beyond the original Volume of Fluid (VOF) method to increase the accuracy of boundary conditions and interface tracking. FLOW-3D incorporates a special technique, known as the FAVOR ${ }^{\mathrm{TM}}$ (Fractional Area Volume Obstacle Representation) method, which is used to define general geometric regions within rectangular grids. This technique allows for the simplicity of structured gridding while 
maintaining a high level of accuracy in flow dynamics. FLOW-3D’s multi-block meshing is designed to add even more flexibility and efficiency to the finite difference meshing technique, allowing users to efficiently capture complex flow domains and a high level of detail required within the flow domain. In addition, several turbulence models are optional in the FLOW-3D, and the $k-\varepsilon$ model was adopted in this simulation. In this study, FLOW-3D version 9.3.2 was adopted. Figure 6 shows the Graphical User Interface (GUI) of the FLOW-3D and the FAVORized coarse grained slope model.

\section{Grid independence}

In order to get the best compromise between precision/accuracy and computation time of the simulation, grid independence was employed before the formal simulation of wave propagation over coarse grained sloping beach. It is a procedure to find a mesh size out that a coarse mesh gives a solution is invariant with the finer meshes. Grid independence is done to ensure that the solution is independent on the grid size. A $72 \mathrm{~cm} \times 56 \mathrm{~cm} \times 24 \mathrm{~cm}$ submerged breakwater was conducted with three layers of spherical balls which the diameter of the ball is $7.9 \mathrm{~cm}$ in a horizontal wave flume. The water depth is $32 \mathrm{~cm}$ and incident wave height and period are $8.0 \mathrm{~cm}$ and $1.0 \mathrm{sec}$, respectively. The grid independence tests were conducted with 7 different size cubic meshes, i.e. $0.16 \mathrm{~cm}, 0.20 \mathrm{~cm}, 0.25 \mathrm{~cm}$, $0.32 \mathrm{~cm}, 0.4 \mathrm{~cm}, 0.5 \mathrm{~cm}$ and $0.8 \mathrm{~cm}$. Figure 7 shows the sketch of the submerged breakwater and also an example of the FAVORized coarse grained submerged breakwater model with mesh size $0.25 \mathrm{~cm}$.

Snapshots of the influence of mesh size on water wave propagating through the submerged breakwater in different phases are shown in Figure 8. The variance of water surface elevation between different mesh from $0.16 \mathrm{~cm}$ to $0.8 \mathrm{~cm}$ are small that it is not easy to distinguish visually. Figure 9 and Figure 10 shows the velocity component of vertical cross section (z-direction) and horizontal cross section (y-direction) inside the submerged breakwater with different mesh size, respectively. Compare the results of velocity components with the water surface; the grid dependent is more obviously in velocity fields. By the grid independent tests, the velocity profile of vertical and horizontal cross section convergence while mesh size smaller than $0.25 \mathrm{~cm}$. It means that the mesh size should be smaller than 1/32 of the diameter of a spherical ball, in other words, a spherical ball were be divided into 32,768 elements. According to the result, we were set the mesh of the coarse grained sloping beach with $0.25 \mathrm{~cm} \times 0.25 \mathrm{~cm} \times 0.25 \mathrm{~cm}$ around the porous slope for the following study.

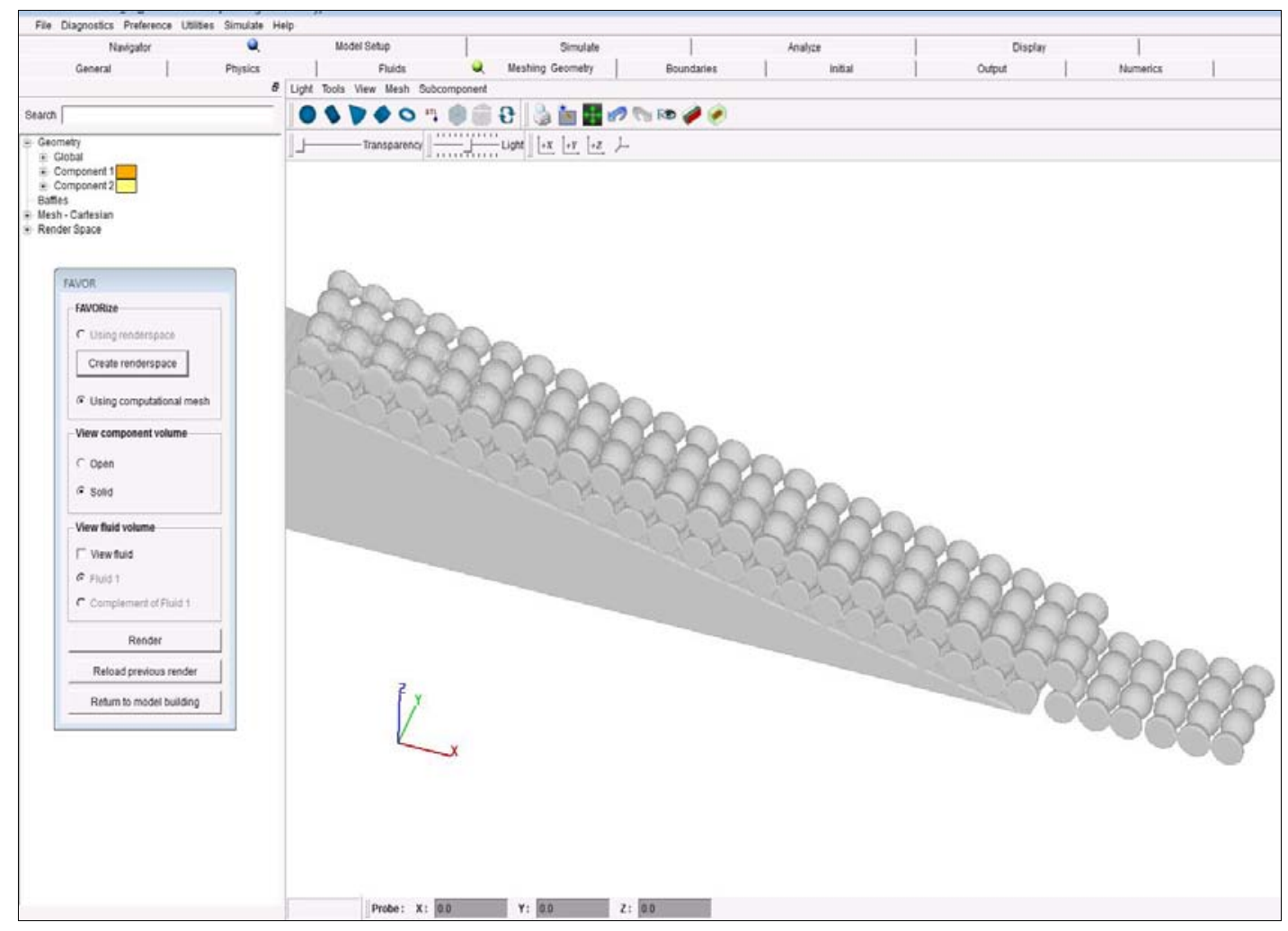

Figure 6. GUI of Flow3D and FAVORized coarse grained slope model. 


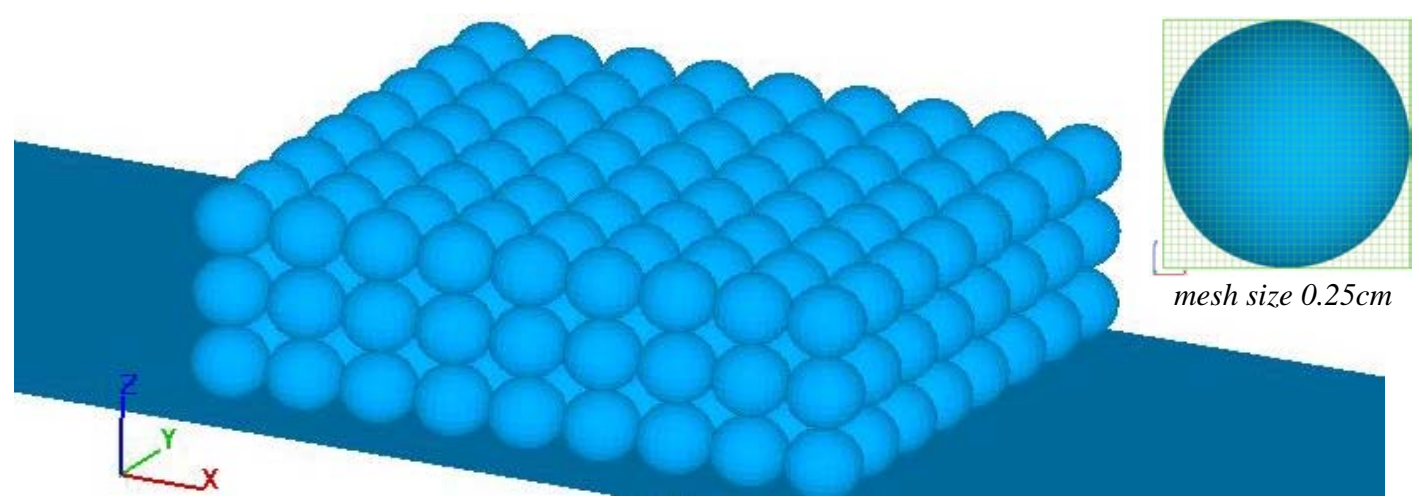

Figure 7. An example of FAVORized coarse grained submerged breakwater model for grid independence test.

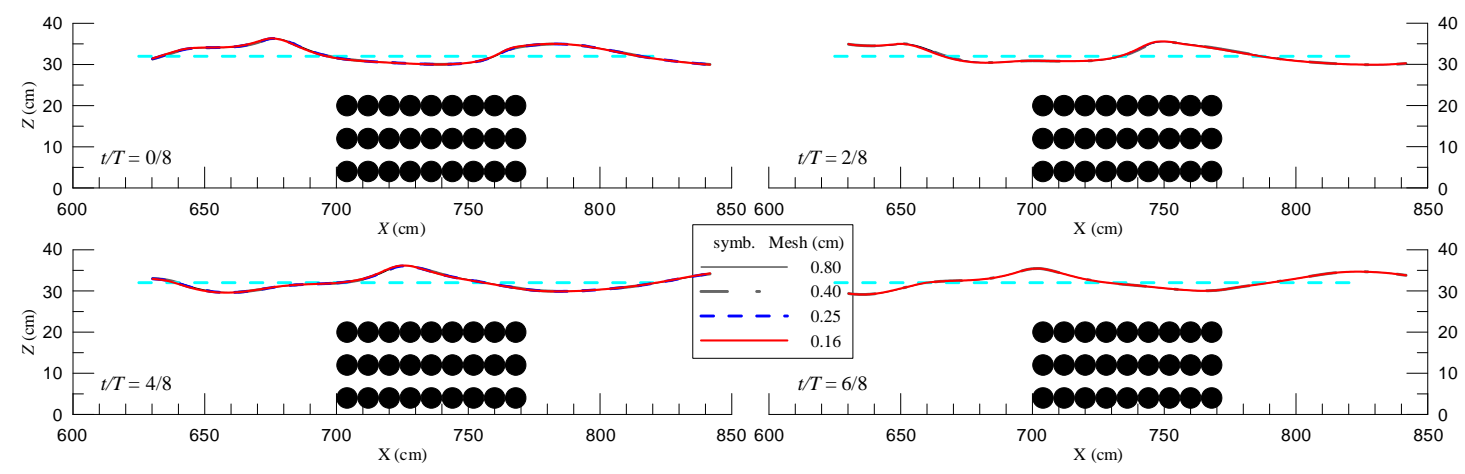

Figure 8. Grid independence test: Influence of mesh size on water wave propagation.
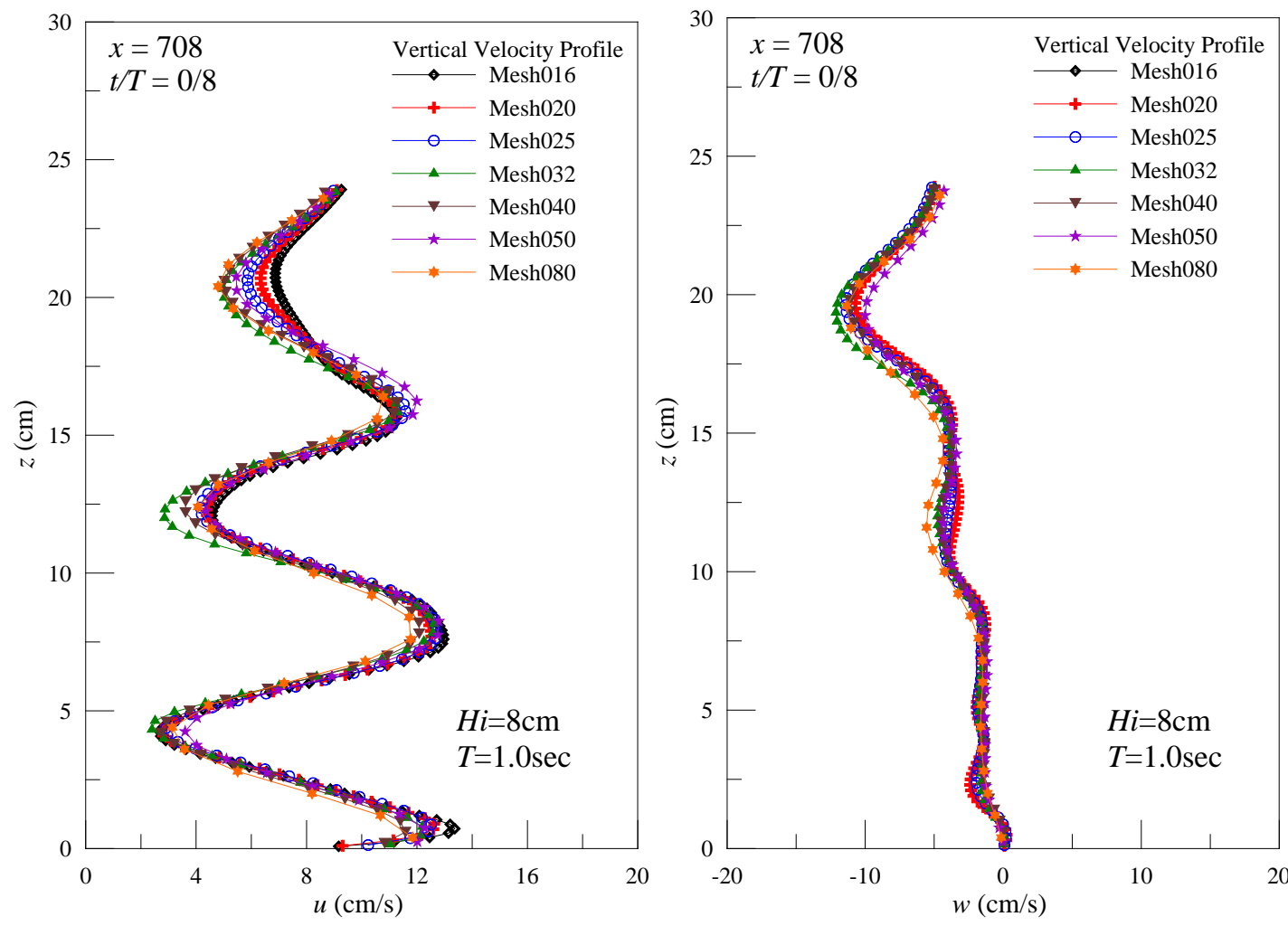

Figure 9. Grid independence test: Influence of mesh size on the velocity of vertical cross section. 

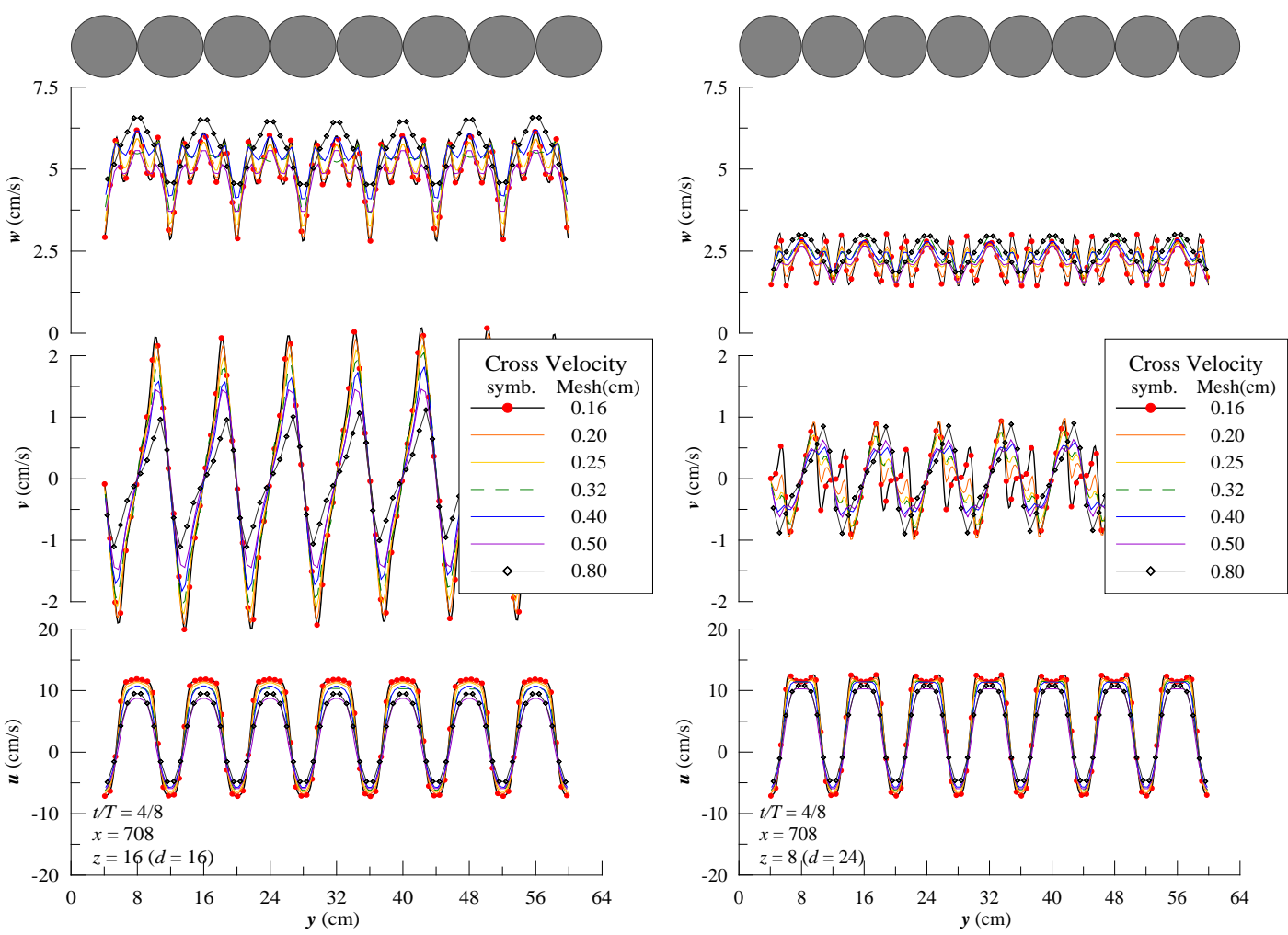

Figure 10. Grid independence test: Influence of mesh size on the velocity of horizontal cross section.

\section{EXPERIMENTAL RESULTS AND NUMERICAL MODEL VALIDATION}

The measurements of water surface and velocity fields under water wave propagating over coarse grained sloping beach surface are investigated in this section.

\section{Water wave propagation}

The comparisons of water surface fluctuation at different position between microscopic 3D direct simulation and experimental data in two different incident wave cases are shown in Figure 11. At position outer the breaking point $(x \geq 48.8 \mathrm{~cm})$, the amplitude and phase from measured and computed results are coincided. However, in the surf zone and swash zone $(x<48.8 \mathrm{~cm})$, there are phase lag exits between experimental and numerical results. Overall, the results shows that direct threedimensional simulations have good agreement with the experimental data.
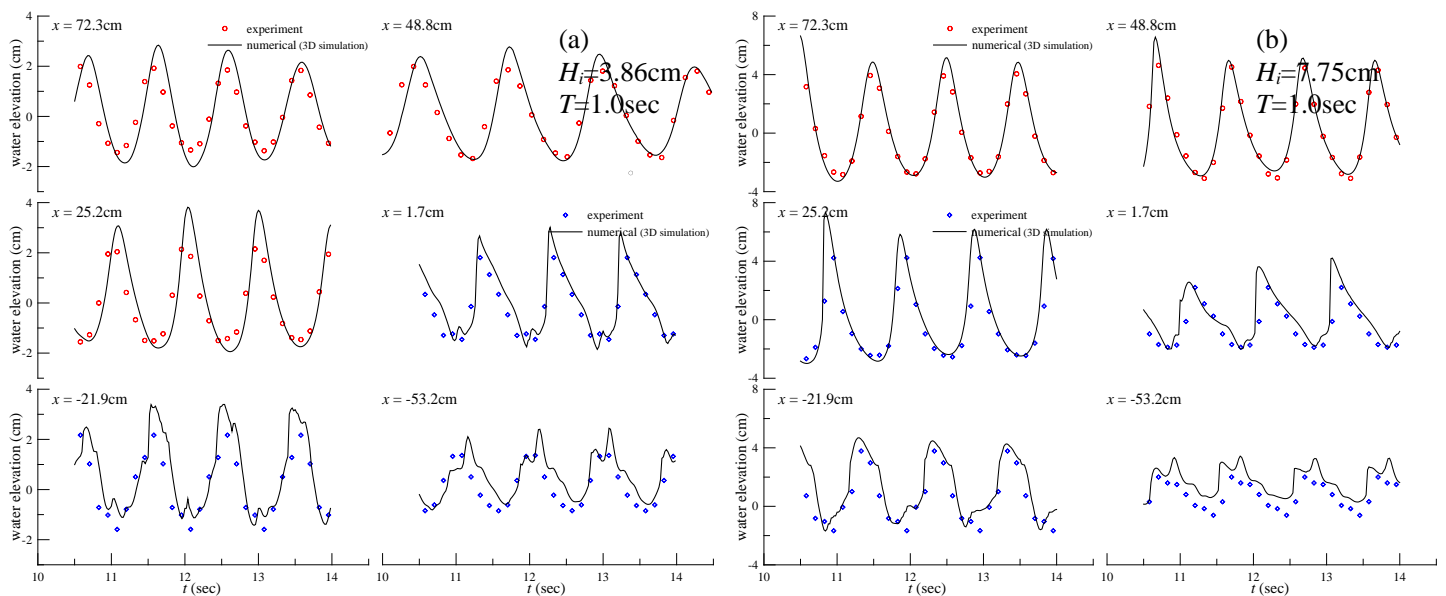

Figure 11. Comparison of water surface water surface fluctuation at different position between microscopic 3D direct simulation and experimental data. (a) $H_{i}=3.86 \mathrm{~cm}, T=1.0 \mathrm{sec}$; (b) $H_{i}=7.75 \mathrm{~cm}, T=1.0 \mathrm{sec}$. 
Velocity field

Figure 12 shows the comparisons of phase velocity profile in $u$ - and $w$ - components at different position between 3D direct simulation and experimental data in two different incident wave cases. Overall, the results shows that direct three-dimensional simulations have good agreement with the experimental data. However, in the surf zone and swash zone $(x<48.8 \mathrm{~cm})$, there are phase lag exits between experimental and numerical results. We have to inform here that the velocity measured by PIV inside the porous layer is only available in the small region between spherical balls that the laser sheets visible by the side view camera.
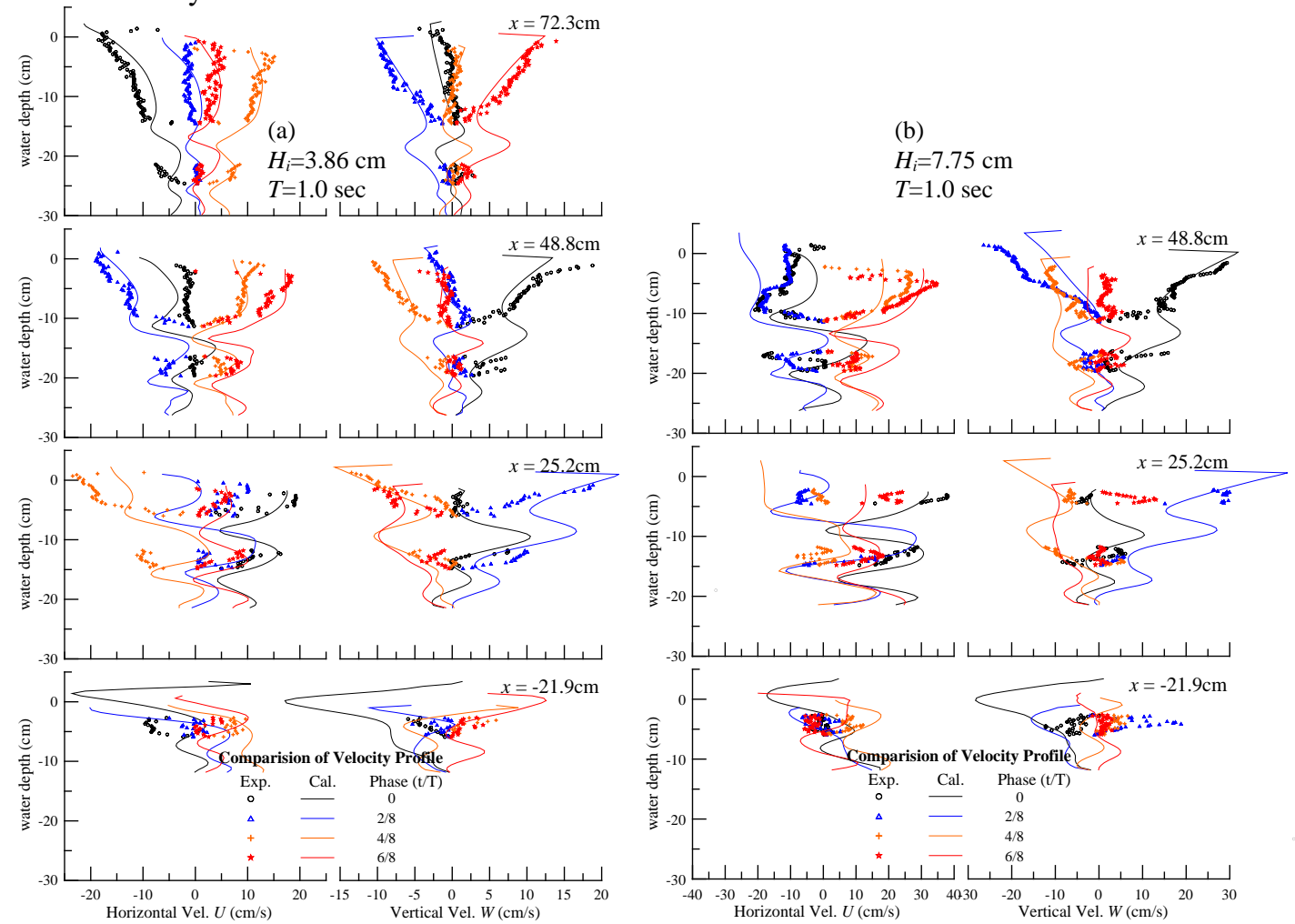

Figure 12. Comparison of velocity profile at different position between microscopic 3D direct simulation and experimental data. (a) $H_{i}=3.86 \mathrm{~cm}, T=1.0 \mathrm{sec}$; (b) $H_{i}=7.75 \mathrm{~cm}, T=1.0 \mathrm{sec}$.
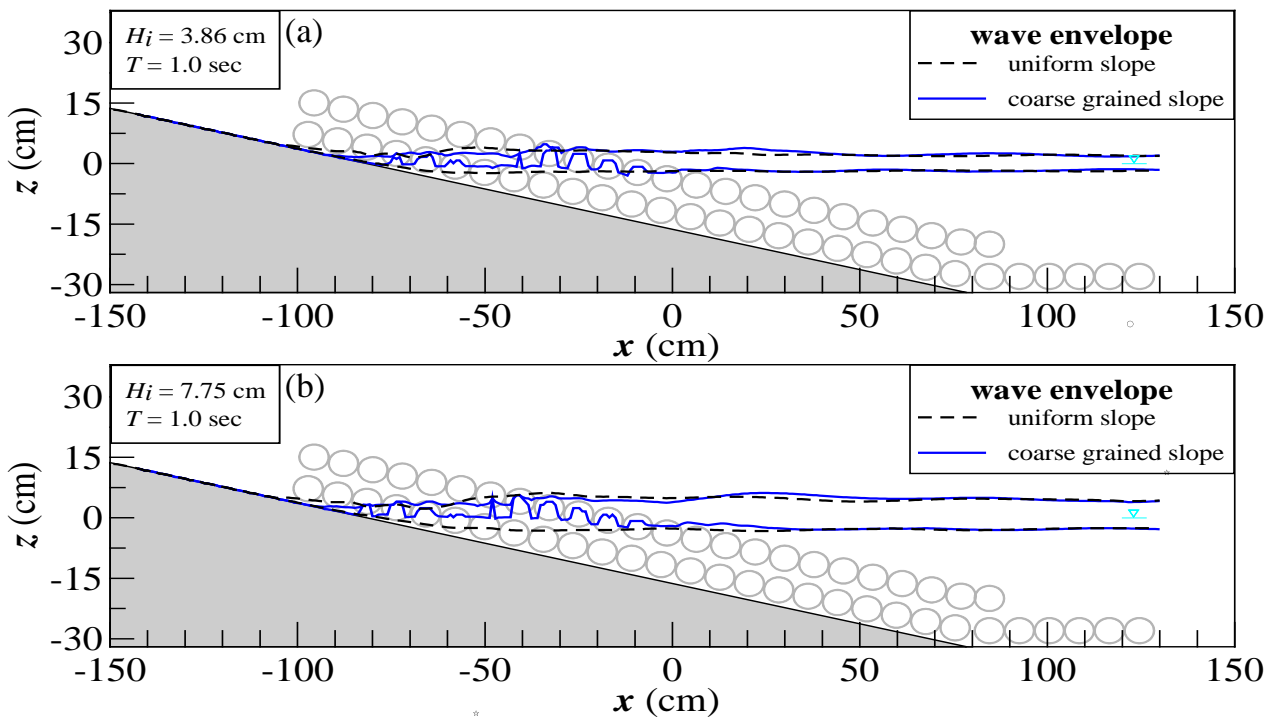

Figure 13. Comparison of wave propagating envelopes over coarse grained slope and impermeable uniform slope. (a) $H_{i}=3.86 \mathrm{~cm}, T=1.0 \mathrm{sec}$; (b) $H_{i}=7.75 \mathrm{~cm}, T=1.0 \mathrm{sec}$. 


\section{RESULTS AND DISCUSSION}

According to the validate discussion in previous section, the microscopic 3D direct simulation for this study by using FLOW-3D have reasonable and reliable results. In this section, the evolution of wave deformation and turbulence over coarse grained sloping beach are investigated based on the numerical results.

\section{Water wave propagation}

Wave propagating on sloping beach has different kinds of deformation, i.e. shoaling, breaking, reflection and run-up/rundown in the swash zone. After integrated the water surface fluctuation in spatio-temporal domain, we have the wave envelope show as Figure 13. In Figure 13(a), the wave envelopes with the incident wave height $H_{i}=3.86 \mathrm{~cm}$ on coarse grained and impermeable uniform slopes are plotted in solid and dash lines, respectively. On the porous bed slope, the wave breaking height $H_{b}$ is $5.42 \mathrm{~cm}$ and run-up maximum reach $x=-92.8 \mathrm{~cm}$. In contrast, wave breaking height $H_{b}$ is $6.32 \mathrm{~cm}$ and run-up maximum reach $x=-104.8 \mathrm{~cm}$ on the impermeable uniform slope. It is clear that the wave fluctuation on porous bed is small due to the bottom friction and influence porosity. The wave energy diminishes due to porous layer is also observed in the case of $H_{i}=7.75 \mathrm{~cm}$ as shown in Figure 13(b). In addition, focus on the envelope in the swash zone, the upper envelope on the porous bed only have a small difference with impermeable ones, but the lower envelope raise up obviously. It should be the concentration of porosity and effect of radiation stress on set-up.

Nonlinear effects will occur during the transmission of the water wave on slope. Here, we also discuss the wave deformation and the change of harmonic wave amplitude. The first four harmonic components of waves are obtained by the Fourier transform. In Fig. 14 and Fig. 15, results for the amplitudes of waves for the run $H_{i}=3.86 \mathrm{~cm}$ and $H_{i}=7.75 \mathrm{~cm}$ are presented. On the wave shoaling process, as the Ursell number increasing, the wave energy transfers from fundamental frequency to 2nd harmonic frequency, and the amplitude of fundamental wave decreases slightly. After wave breaking, the fundamental wave energy decreases rapidly and it transfers into higher order harmonic. In the swash zone, the amplitudes of each harmonic decrease obviously due to the diminution of energy by the effect of intrinsic permeability and turbulent drag.

\section{Turbulent kinematic energy}

Figure 16 and 17 shows the global distributions of the TKE with color magnitude scale for different incident wave heights. In each figure, right column shows the TKE distribution in different phase over impermeable uniform slope and left column represents the TKE distribution that wave propagating over the coarse grained sloping bottom. For impermeable case, significant and stronger TKE density is successively generated in the front face of the bore. The computed maximum value of TKE in the established bore region for two different incident wave heights are greater than $360 \mathrm{~cm}^{2} \mathrm{~s}^{-2}$ and $1200 \mathrm{~cm}^{2} \mathrm{~s}^{-2}$, respectively. The turbulence continues to be generated during the bore propagation and is elongated to fill the whole wave crest. On the other hand, the turbulent energy distributed over coarse grained sloping beach in different incident heights are not obviously not only on the magnitude but also the incursions depth. The distribution of the turbulent energy density on porous bottom only occurs above the mean water level in the surf zone and swash zone. The significant magnitude of the turbulent energy density for the runs of $H_{i}=3.86 \mathrm{~cm}$ and $H_{i}=7.75 \mathrm{~cm}$ are less than $180 \mathrm{~cm}^{2} \mathrm{~s}^{-2}$ and $800 \mathrm{~cm}^{2} \mathrm{~s}^{-2}$, respectively.

\section{Turbulent dissipation rate}

The temporal and spatial distributions of the turbulence dissipation rate $\varepsilon_{D}$ induced by surf-zone breaking waves over two different kinds of bottom slope are shown in Figure 18 and 19 with two incident wave height cases. The left panel of Figure 18 shows the global distributions of turbulent dissipation over a coarse grained sloping beach in 5 phases of a wave, and the right panel of Figure 18 shows the turbulent dissipation over impermeable uniform slope. For impermeable bed, significant dissipation occurs only in frontal region of the wave crest at the incipience of wave breaking in the outer surf zone. In this stage, the turbulence dissipation rate is increasing but not too high. In the most intense wave breaking region, high turbulent dissipation occurs in the frontal crest region above the mean water level. In the inner surf zone, high turbulent dissipation occurs in the crest region and also occurs below the trough level. Remarkably, it is observed that the dissipation is coming from the crest region where the turbulence is generated and stretched shoreward. In contrast, the distribution of turbulence dissipation rate over coarse grained sloping bottom is otherwise very low which compares 
with the impermeable bottom. Significant dissipation occurs only in the bore-established region and is limited in the region of upper layer of spherical balls which above the mean water level. But noticeable difference of the distribution of turbulence dissipation rate between porous and impermeable slope are the spread region. Due to the effect of porous bottom, the turbulence dissipation distributes from outer of surf zone to the run-up limitation.

Compare the Figure 16 to Figure 19, we may find that the evolutions of the turbulent dissipation in the surf zone and the distributions of turbulent kinematic energy have well correlation. This may imply that turbulent kinematic energy induced by wave breaking dominate the mechanism of turbulent dissipation in the surf zone. This corresponds to the turbulence similarity reported by Huang et al. (2009).
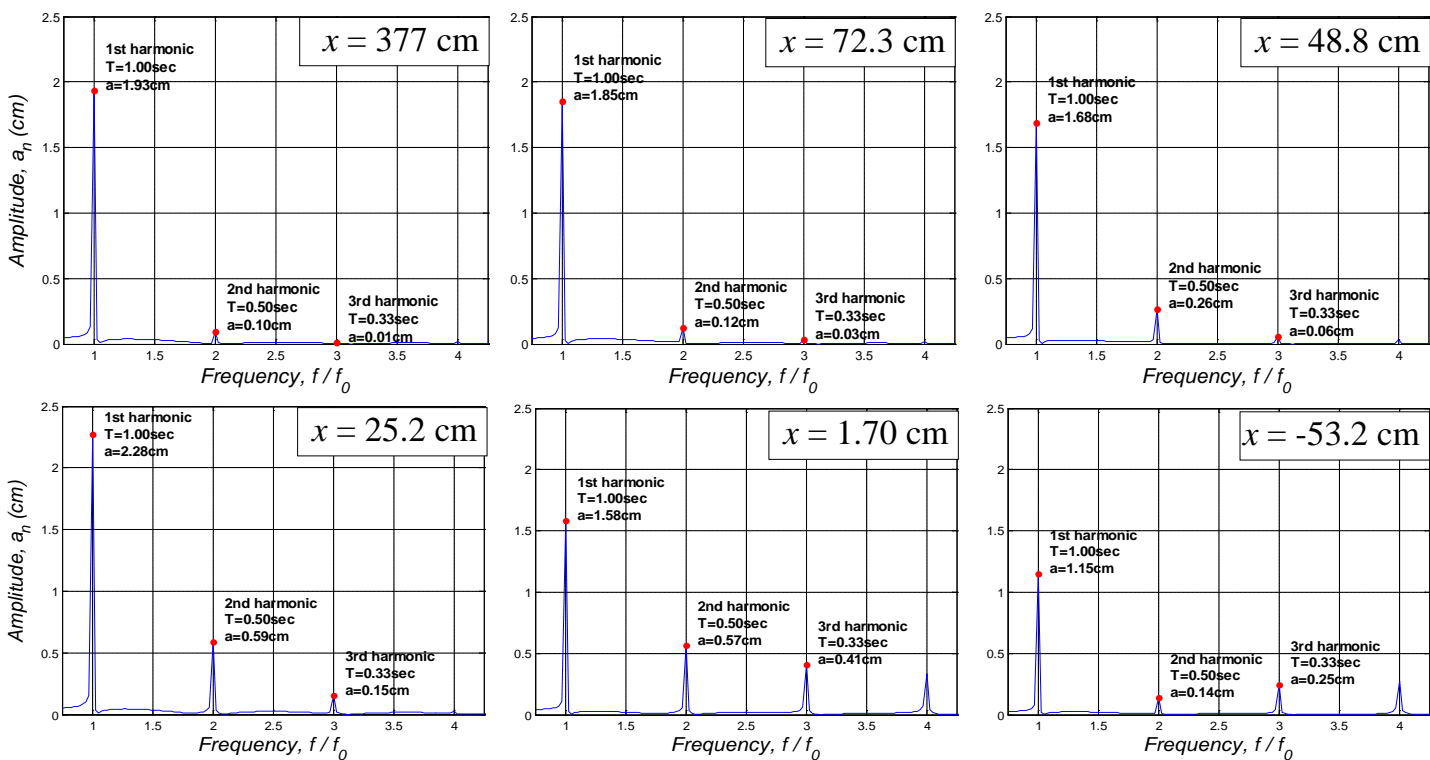

Figure 14. Wave deformation process and the change in harmonic wave amplitude. $H_{i}=3.86 \mathrm{~cm}, T=1.0 \mathrm{sec}$.
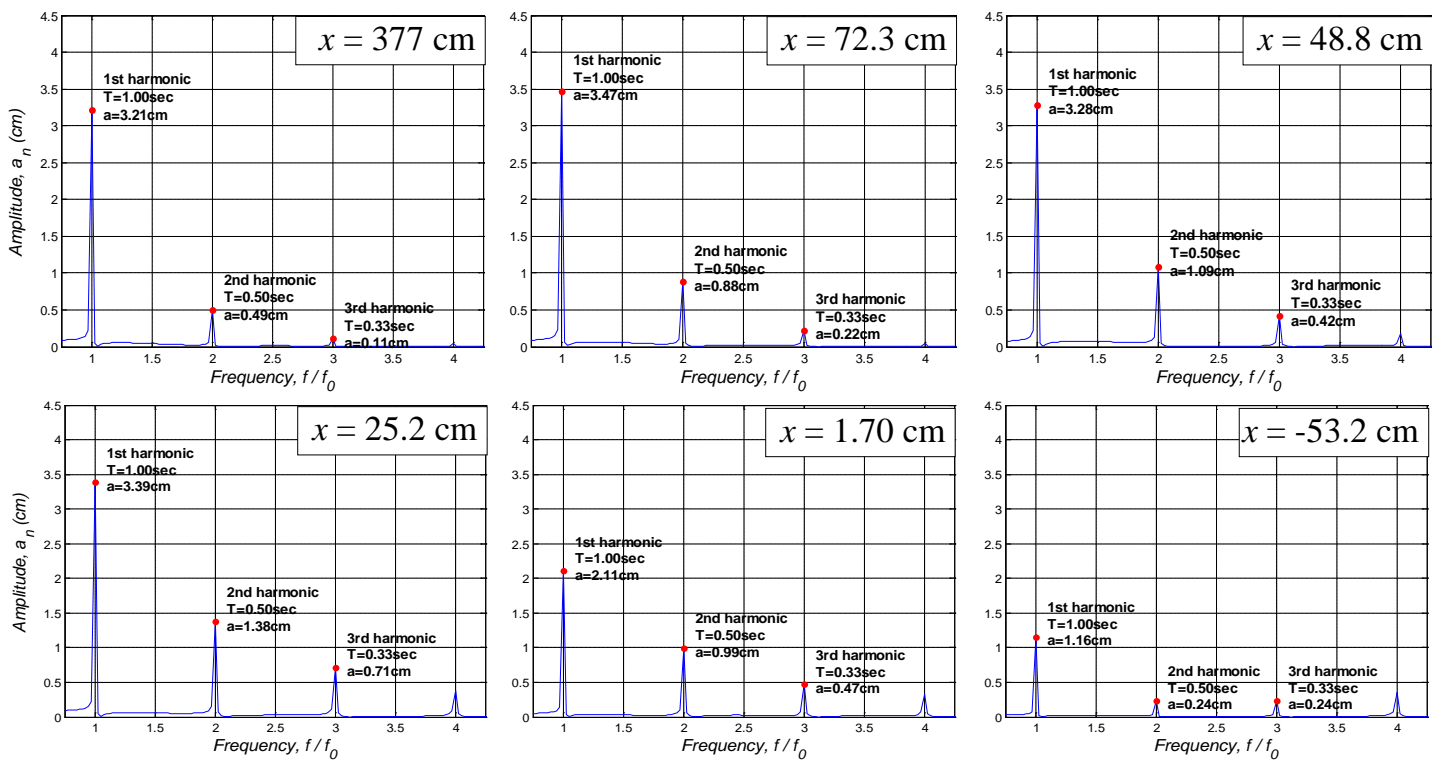

Figure 15. Wave deformation process and the change in harmonic wave amplitude. $H_{i}=7.75 \mathrm{~cm}, T=1.0 \mathrm{sec}$. 

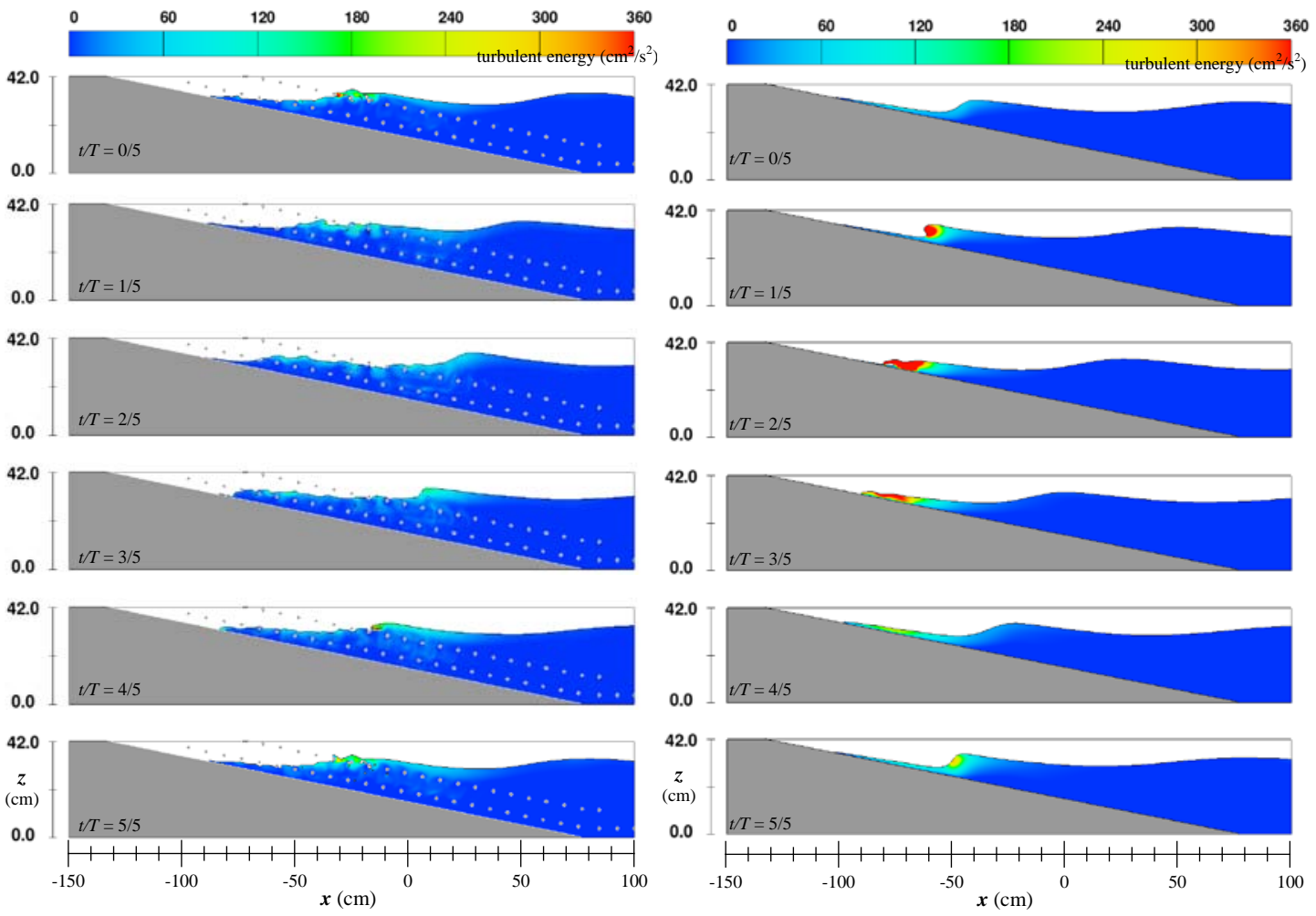

Figure 16. Comparison of turbulent energy over coarse grained slope and impermeable uniform slope at cross section $y=8 \mathrm{~cm}$. $H_{i}=3.86 \mathrm{~cm}, T=1.0 \mathrm{sec}$.
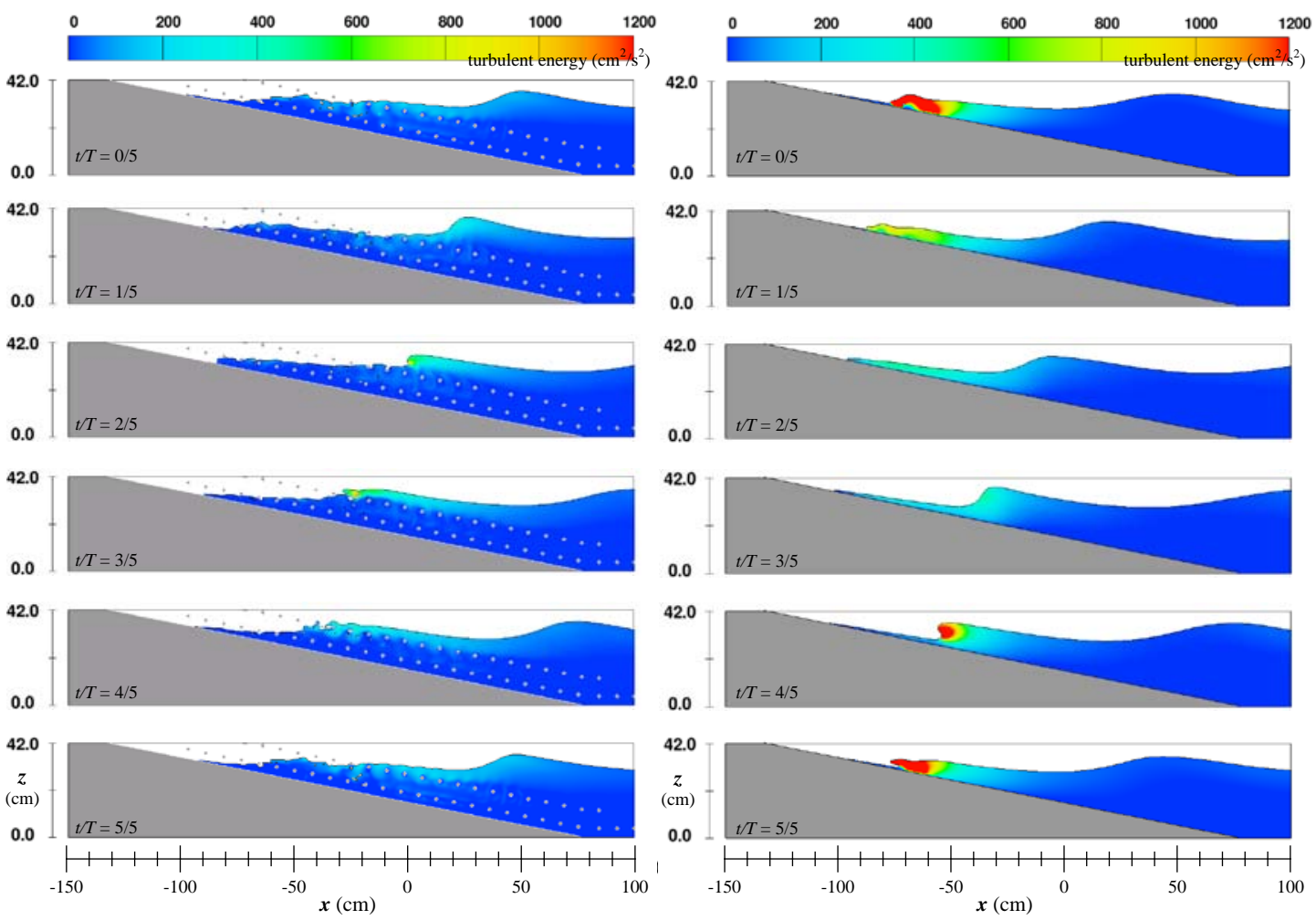

Figure 17. Comparison of turbulent energy over coarse grained slope and impermeable uniform slope at cross section $y=8 \mathrm{~cm} . H_{i}=7.75 \mathrm{~cm}, T=1.0 \mathrm{sec}$. 

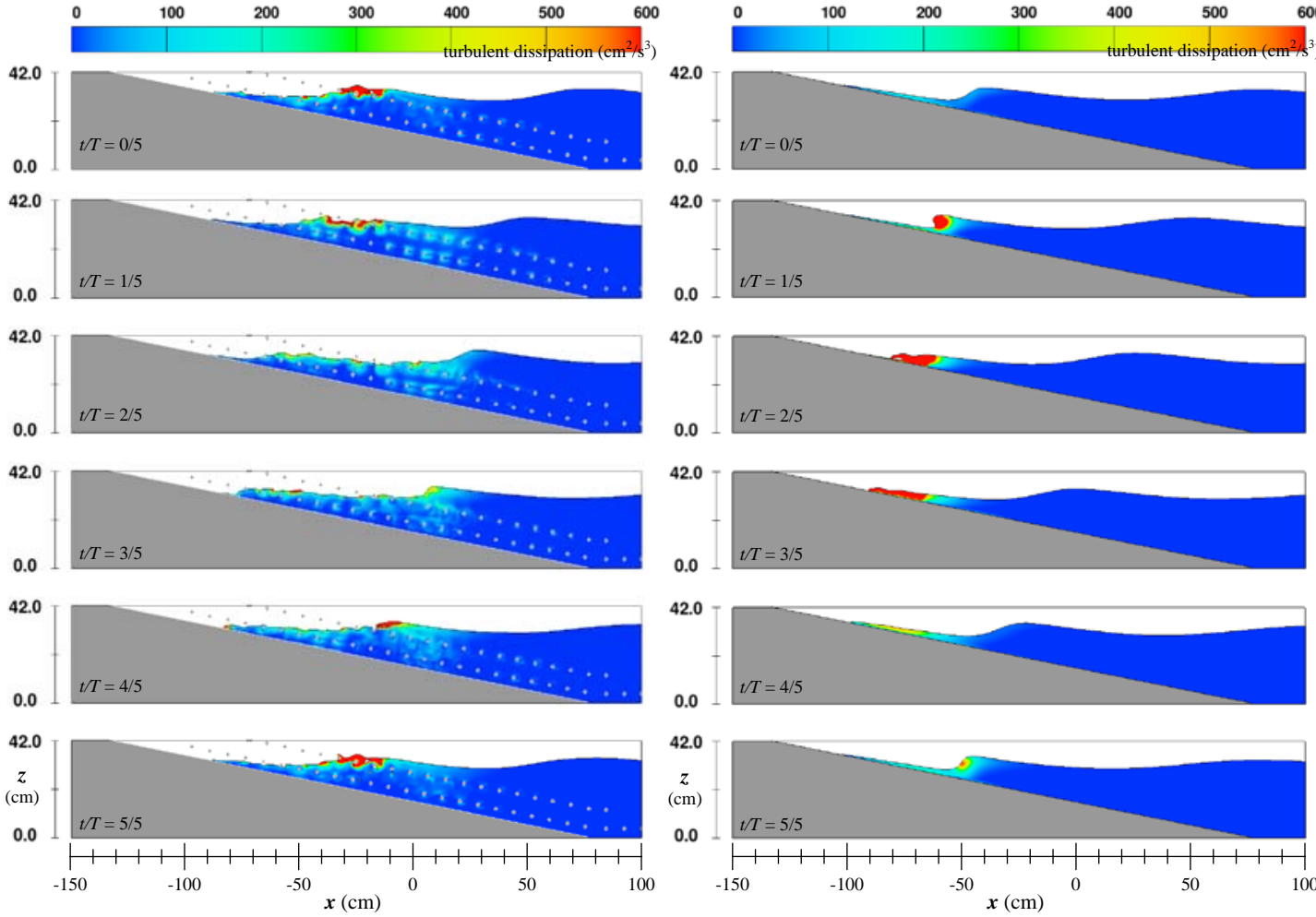

Figure 18. Comparison of turbulent dissipation over coarse grained slope and impermeable uniform slope at cross section $y=8 \mathrm{~cm} . H_{i}=3.86 \mathrm{~cm}, T=1.0 \mathrm{sec}$.
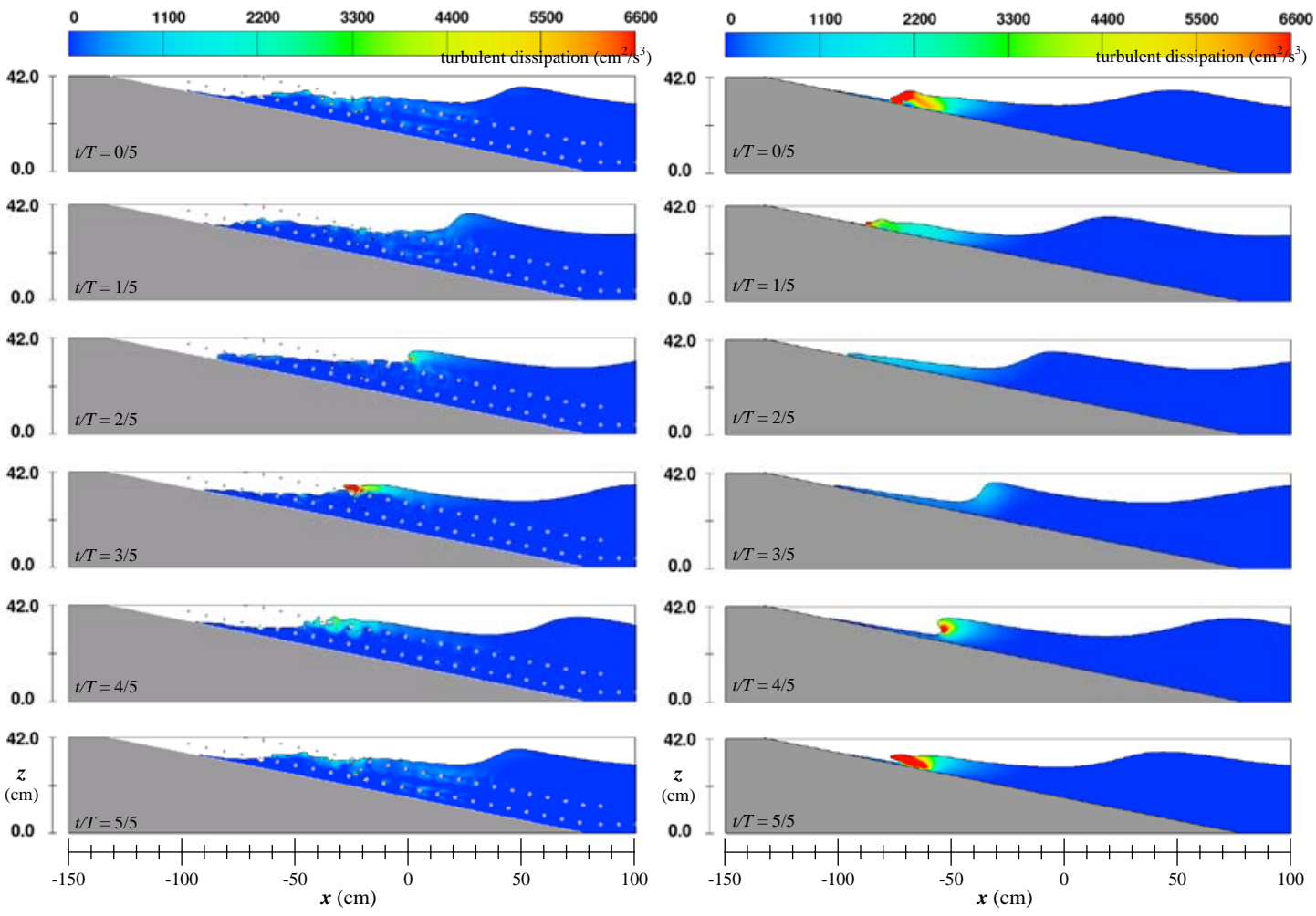

Figure 19. Comparison of turbulent dissipation over coarse grained slope and impermeable uniform slope at cross section $y=8 \mathrm{~cm} . H_{i}=7.75 \mathrm{~cm}, T=1.0 \mathrm{sec}$. 


\section{CONCLUSION}

In this study, the wave propagation over coarse grained sloping beach were respectively measured using a non-intrusive image based method (i.e. particle image velocimetry and digital image process) in a glass walled wave flume and computed by computational fluid dynamics software. In experimental study, a mosaic technique was used to integrate a large field of view (FOV) from 11 sub-FOVs. Several interesting findings regarding different issues under this study are summarized as the following: On the technique of experiment:

1. Subsequent digital image processing (DIP) techniques that including image enhancement, coordinate transformation and edge detection were developed to get the information of wave propagating from the images.

2. The PIV and DIP techniques offer a possibility for measuring full scale spatio-temporal information of the wave motions and velocity field within / without the porous sloping bed without instructive instrument.

On the validation of computational fluid dynamics numerical model:

1. Based on the results of grid independent tests, the mesh size smaller $1 / 32$ of the diameter of a spherical ball should be adopted for the microscopic direct three-dimensional simulation over this kind of coarse grained sloping beach.

2. According to the comparison of the wave and velocity data of hydraulic physical model with computational results, the direct three-dimensional simulations method can offer results agreement with the experimental data in the global regions.

3. The direct 3D simulations can resolve the wave and velocity profile more complete and reasonable descriptions from outer to the inner porous layer and it is true no matter in the surf zone, swash zone and within the porous layer.

On the wave propagation over coarse grained sloping beach:

1. Compare with impermeable slope, the strength of turbulent energy and turbulent dissipation around coarse grained sloping beach is not obviously while waves propagating on the slope.

2. The maximum turbulent kinematic energy and turbulent dissipation rate occurs around the surface of spherical ball layer inner the surf zone.

\section{ACKNOWLEDGMENTS}

This study was financially supported by the National Science Council of Taiwan under grant number NSC96-2221-E-006-331-MY3. The support of Landmark integrated project of the top university of National Cheng Kung University through Grant R046 is also acknowledged.

\section{REFERENCES}

Abdel-Aziz Y. I. and H. M. Karara. 1971. Direct linear transformation from comparator coordinates into object space coordinates in close range photogrammetry”, in: Proc. of the ASP/UI Symposium, Close-Range Photogrammetry, 1-18.

Dattatri, J., H. Raman, and N. Jothishankar. 1978. Performance characteristic of submerged breakwaters. Proc.16th Conf. Coastal Eng., Hamburg, ASCE, 2153-2171.

Iwasaki, T. and A. Numata. 1970. Experimental studies on wave transmission of a permeable breakwater constructed by artificial blocks. Coast. Eng. Jpn., 13, 25-29.

Liu, P. L.-F., P. Lin, K. A. Chang, and T. Sakakiyama. 1999. Numerical modeling of wave interaction with porous structures. J. Waterw. Port, Coast. Ocean Eng., 125, 322-330.

Losada, I. J., M. A. Losada, and F. L. Martin. 1995. Experimental study of wave-induced flow in a porous structure. Coastal Eng., 26, 77-98.

Losada I. J., R. Silva, M. A. Losada. 1996. Interaction of non-breaking directional random waves with submerged breakwaters, Coastal Eng., 28, 249-266.

Madsen, K. L. 1974. Effect of chlorhexidene mouthrinse and periodontal treatment upon bacteremia produced by oral hygiene procedures. Scand. J. Dnt. Res., 82, 1-7.

Mendez F., I. J. Losada and M. A. Losada. 2001. Wave-induced mean magnitudes in permeable submerged breakwaters. J. Waterw. Port, Coast. Ocean Eng., 127, 1-9.

Otsu N. 1978. A threshold selection method from gray level histogram, IEEE Trans. on System, Man, and Cybernetics, 8, 62-66.

Putnam, J. A. 1949. Loss of wave energy due to percolation in a permeable sea bottom. Trans. Am. Geophys. Union, 30, 349-356. 
Reid, R. O. and K. Kajiura. 1957. On the damping of gravity waves over a permeable sea bed. Trans. Am. Geophys. Union, 38, 362-666.

Rojanakamthorn, J., M. Isobe and A. Watanabe. 1989. A mathematical model of wave transformation over a submerged breakwater. Coast. Eng. Jpn., 32, 2, 209-234.

Sakakiyama, T., R. Kajima and N. Abe. 1991. Numerical simulation of wave motion in and near breakwaters, Proc. of 38th Japanese Conference on Coastal Eng., JSCE, 545-550.

Sakakiyama, T. and R Kajima, 1992. Numerical simulation of nonlinear wave interacting with permeable breakwaters, Proc.23th Conf. Coastal Eng., ASCE, 1517-1530.

Sollitt, C. K. and R. H. Cross. 1972. Wave Transmission Through Permeable Breakwaters, Proc. 13th Inter. Conf. on Coastal Eng., ASCE, 1827-1846.

Tsai, C. P., H. B. Chen, and F. C. Lee. 2006. Wave transformation over submerged permeable breakwater on porous bottom. Ocean Eng., 33, 1623-1643.

Van Gent, M.R.A. 1995a. Wave interaction with permeable coastal structures. Delft University of Technology, Delft, The Netherlands.

Van Gent, M.R.A. 1995b. Porous flow through rubble-mound material. J. Waterw. Port, Coast. Ocean Eng., 121, 176-181.

Wurjanto, A. and N. Kobayashi. 1993. Irregular wave reflection and run-up on rough permeable slopes. J. Waterw. Port, Coast. Ocean Eng., ASCE, 119, 537-557.

Wang, D.C. and A. Khalili. 2003. Flow visualization and quantitative measurements inside porous media by particle image velocimetry, Proc. of SPIE, 5058, 232-239. 